\title{
La comunicación no verbal. Importancia en el proceso de formación de profesionales de lenguas extranjeras
}

\author{
Lic. Rolando García Acosta \\ Universidad de Cienfuegos \\ rpublicas@ranluna.cfg.tur.cu
}

\author{
MSc. Dianalei Maza Amores \\ Universidad de Cienfuegos \\ rpublicas@ranluna.cfg.tur.cu
}

Recibido: 07 de marzo de 2017
Palabras claves: comunicación, competencia comunicativa, lenguaje corporal, turismo.
Keywords: communication, communicative competence, body language, tourism.
Aceptado: 23 de mayo de 2017

\section{RESUMEN}

Los humanos somos seres sociales por naturaleza y, por lo tanto, tenemos la necesidad de relacionarnos con los demás y dejar constancia de nuestra existencia. El siguiente artículo pretende mostrar la importancia que juega la comunicación no verbal en el proceso de formación de los profesionales de lenguas extranjeras y sobre todo en la competencia comunicativa de los mismos en la segunda lengua. El artículo presenta la importancia del lenguaje corporal, específicamente de los gestos, las expresiones faciales y el comportamiento de la mirada entre los interlocutores y sobre todo los obstáculos que se pueden presentar durante una comunicación intercultural. Para esto se llevó a cabo el análisis de documentos: planes de estudio, programa de la disciplina Idioma Inglés, y el método empírico a través de las entrevistas a profesionales del sector del turismo, en la provincia de Cienfuegos, Cuba.

\begin{abstract}
Humans are social beings by nature and, therefore, we have the need to inter- act with others and record our existence. The present article is intended to show the importance of non-verbal communication in the training process of language professionals. The article presents the importance of body language, especially gestures, facial expressions and look behavior among interlocutors and especially the obstacles that can appear in an intercultural communication. In order to accomplish this research, documents analysis, English language Syllabus and interviews to workers from the tourism sector in Cienfuegos, Cuba were analyzed.
\end{abstract}




\section{INTRODUCCIÓN}

En la vida cotidiana, constantemente se envían mensajes no verbales a otras personas (gestos, señalamos con el dedo, miradas etc.), que son mucho más importante de lo que se cree. La comunicación corporal, antes que el lenguaje en términos evolutivos, es una parte esencial del sistema de comunicación, y el vehículo para muchas transacciones humanas fundamentales que el discurso solo no puede comunicar.

La comunicación no verbal (CNV) surge con los indicios de la especie humana antes de la evolución del lenguaje propiamente dicho. Los animales también muestran ciertos tipos de comunicación no verbal. Es importante no confundir la "comunicación no verbal" con la "comunicación no oral" ya que existen formas de comunicación "verbal" (es decir, con estructura lingüística o sintáctica) no orales, como por ejemplo la comunicación escrita y las lenguas de señas. Igualmente existe comunicación no verbal que puede ser producida oralmente, como los gruñidos o sonidos de desaprobación. En los seres humanos, la CNV es frecuentemente paralingüística, es decir acompaña a la información verbal matizándola, ampliándola o enviando señales contradictorias.

Debido a las transformaciones y necesidades actuales de la sociedad, se forman profesionales en diferentes áreas. La preparación de profesionales en lenguas extranjeras es una necesidad actual de suma importancia. Una preparación adecuada de estos profesionales, basado en la comunicación intercultural permitiría una mayor profesionalidad de los mismos y sobre todo mayor seguridad ante situaciones para las que han sido preparados. Parte de esta Comunicación Intercultural la forma la Comunicación No Verbal.

\section{DESARROLLO}

La comunicación no verbal ha recibido menor atención y estudio científico que la verbal, pues consiste en un modo de transmisión de información menos estructurado y de más difícil interpretación. Antes de 1950 se conocen pocos trabajos publicados que profundizaran en aspectos de la comunicación no verbal, ya que ésta no se consideraba un objeto digno de interés científico. Antes del estudio científico de la comunicación no verbal, el lenguaje no verbal no había pasado de la descripción más o menos extensa de anécdotas y observaciones curiosas, como es el caso de algunas descripciones presentes en la obra de Charles Darwin "The Emotions in Man and Animals", escrita en 1872.

Darwin sugirió la posibilidad de que los humanos tienen, en todos los contextos culturales, elementos de expresión que les son comunes. Además, destacó la importancia de la comunicación y de la expresión en la supervivencia biológica. También David Efron, con su obra Gesture and Environment (1941), estableció la importancia del papel de la cultura en la formación de muchos de nuestros gestos. 
En la década de 1950 comenzó un despegue de la investigación en todas las áreas de la comunicación humana. En lo concerniente al área no verbal se destacan hechos significativos:

- $\quad$ Aparece Introduction to Kinesics (1952), del antropólogo Ray Birdwhistell.

- $\quad$ El psiquiatra Jürgen Ruesch y el fotógrafo Weldon Kees publican el primer libro que utilizó el término "no verbal", Nonverbal Communication (1956). Esta obra ofrecía una visión del tema acompañada de una amplia documentación gráfica.

- $\quad$ Otro antropólogo, Edward T. Hall, publicó The Silent Language (1959), tras varios años de investigación del uso del espacio por los seres humanos: la proxémica. Un estudio más detallado sobre este tema apareció más tarde, en 1996: The Hidden Dimension.

- $\quad$ Otros investigadores han realizado importantes contribuciones, como Ray L. Birdwhistell, Flora Davis, Allan Pease, Desmond Morris y Paul Ekman.

La comunicación no verbal es el proceso de comunicación mediante el envío y recepción de mensajes sin palabras, es decir, se da mediante indicios, signos y que carecen de sintaxis, es decir, no tienen estructura sintáctica por lo que no pueden ser analizadas secuencias de constituyentes jerárquicos.

Estos mensajes pueden ser comunicados a través de gestos, lenguaje corporal o postura, expresión facial y el contacto visual, la comunicación de objetos tales como ropa, peinados o incluso la arquitectura, o símbolos y la infografía, así como a través de un agregado de lo anterior, tales como la comunicación de la conducta. La comunicación no verbal juega un papel clave en el día a día de toda persona.

Las características más generales de la comunicación no verbal son su no discrecionalidad y que además no tiene un orden secuencial o lineal. En una forma discrecional de comunicación no existe semejanza entre los elementos del código y los significados subyacentes. La forma analógica conserva dos significados: el del emisor y el de receptor; y la comunicación es posible en la medida en que ambos coincidan.

Habitualmente para comunicarnos utilizamos una serie de elementos que apoyan nuestras ideas y le dan significado a lo que expresamos. Estos factores se enmarcan dentro de lo que no es verbalizado por el lenguaje hablado. Son los que se presentan a continuación:

\section{A. Lenguaje Icónico:}

Son las imágenes de los objetos, su representación simbólica. Poseen una doble dimensión, esto es que una ilustración, que se entiende es gráfica, también tiene una explicación escrita. Pertenecen a este lenguaje la señal vial de tránsito, los letreros que vemos en las calles de la ciudad, los medios de comunicación escritos, sean afiches o publicidad; las obras artísticas: esculturas y pinturas. En él se engloban 
muchas formas de comunicación no verbal: código Morse, códigos universales (sirenas, Morse, Braylle, lenguaje de los sordomudos), códigos semi-universales (el beso, signos de luto o duelo), códigos particulares o secretos (señales de los árbitros deportivos).

\section{B. Lenguaje Corporal:}

Los gestos y movimientos que el ser humano realiza, el tono de voz, la ropa e incluso el olor corporal también forman parte de los mensajes cuando nos comunicamos con los demás.

\section{Lenguaje kinésico:}

Son los gestos, movimientos del cuerpo, postura del mismo y las expresiones faciales que utilizan los hablantes, sean conscientes o inconscientes.

En ocasiones estos gestos hablan mucho más que las propias palabras, es así que, si se dice estar interesado en un tema específico, pero el rostro está diciendo lo opuesto y la expresión de éste es de aburrimiento, se puede concluir que la persona se contradice y que realmente no está pendiente de la exposición.

\section{Lenguaje Proxémico:}

Es el uso que se le da al espacio físico donde se desenvuelve el hablante y también a la percepción que éste tiene de su entorno cercano. Es la cercanía o distancia que se tiene al comunicar, cuán lejos o próximo se está del otro y esto depende del grado de confianza y del tipo de interacción que se quiera entregar.

De esta forma será distinto el acercamiento entre dos amigos que dialogan y se conocen, que un emisor hablando a un grupo de oyentes en una conferencia, donde estará en un escenario lejano al público. Ahora bien, hay ocasiones en que la proximidad no se puede evitar, aun cuando los que nos rodean no nos sean cercanos y esto ocurre en la locomoción colectiva, en las filas de los bancos, recitales de música o en los ascensores.

Existen manifestaciones que ayudan a comprender en qué casos se da el Lenguaje No Verbal.

Los gestos: Movimientos que realiza el cuerpo para enfatizar lo que se quiere decir ante un receptor.

El rostro: Cambios de expresión brindados por el rostro, también transmiten mucha información.

La mirada: Lenguaje utilizado para manifestar afecto, burla, admiración, cariño y otros. 
La apariencia personal: Son manifestaciones de nuestra apariencia exterior, es decir de la forma como nos vestimos, y a través de ello queremos comunicar algo.

Las conductas inconscientes: Lo expresamos cuando hacemos algunas acciones sin darnos cuenta, y estas, comunican el estado emocional en el cual nos encontramos.

La comunicación no verbal actúa como refuerzo para la comunicación verbal, es muy usada por todos los seres humanos, y muchas veces ésta se manifiesta independientemente. Según estudios realizados Mackay \& Associates en la comunicación el $55 \%$ del mensaje llega a través del lenguaje corporal, $38 \%$ es voz y solo un $7 \%$ son palabras.

La comunicación corporal, evolutivamente anterior al lenguaje verbal estructurado, es una parte esencial del sistema de comunicación humano y de muchos primates. En los humanos modernos el lenguaje no verbal tiene sentido paralingüístico y resulta importante en muchos intercambios comunicativos humanos que complementan adecuadamente el discurso verbal.

\section{El lenguaje gestual y su dimensión cultural}

Desafortunadamente, no existe ningún libro que hable de todas las reglas del comportamiento humano ni de la comunicación no verbal y ordenar los gestos de todo nuestro planeta es intentar catalogar los rostros de la misma raza. Incluso dentro de un mismo país, puede no existir un acuerdo unánime sobre el significado exacto de cada gesto. Por lo tanto, las siguientes líneas son para utilizar como directrices generales.

\section{El saludo}

El apretón de manos, como elemento de comunicación no verbal, ha sido adoptado casi en todo el mundo como forma habitual de saludar a una persona. Sin embargo, hay saludos tradicionales, como la reverencia, que permanece todavía en países asiáticos. La forma firme o suave de dar la mano a las personas, también forma parte de la del lenguaje no verbal y los diferentes rasgos de cultura.

\section{Movimientos corporales y faciales}

Movimiento de la cabeza: en muchos lugares, aunque no es universal en todas las culturas)

mover la cabeza de arriba abajo indica "sí"; sacudirla de un lado a otro significa "no". En otros países, como Bulgaria, Grecia, Turquía los mismos desplazamientos de la cabeza son interpretadas justamente al revés. 
Ojos: en la cultura europea, estadounidense, canadiense, británica y judía, es importante sostener la mirada mientras hablamos con los demás, sin importar el sexo o la edad. Este mismo gesto es considerado falta de respeto en ciertas condiciones para la población de África: un niño no puede mirar directamente a un adulto y una mujer oriental no debe tener contacto ocular prolongado con un hombre extraño. En países como Japón, Tailandia o Corea, una mirada a los ojos es considerada señal de intimidación.

Aunque el tema es amplio y a continuación se expondrán los principales gestos y actitudes que pueden ayudar en la vida cotidiana y en los negocios. La mayoría de los gestos y movimientos que utilizamos habitualmente, vienen condicionados por el entorno en el que se haya crecido. Los matices culturales, son de gran importancia en el lenguaje corporal. También el entorno familiar, tiene una clara influencia en el comportamiento y en la manera de "hablar con el cuerpo".

\section{Implicaciones Pedagógicas}

Las razones por las que se deben incluir actividades sobre la CNV en las clases de lenguas extranjeras, es porque el comportamiento quinésico puede reducir la ambigüedad del mensaje hablado, facilita la comunicación al incrementar la redundancia del mensaje. De acuerdo con Pennycook (1985): "La competencia comunicativa se limita cuando el estudiante está privado del auténtico input en su totalidad, ambos visual y sonoro que permiten en su conjunto alcanzar tal competencia".

Por lo que los profesores de lenguas extranjeras podrían considerar el uso de materiales audiovisuales que le proveerán a los estudiantes la oportunidad de incrementar su conciencia sobre el uso apropiado de la CNV, y, por consiguiente, el comportamiento de las diferentes culturas a las que podría enfrentarse.

En esencia, es preciso emplear actividades y materiales dónde los comportamientos verbales y no verbales se complemente entre ellos. Dentro de los mismo encontramos el uso de videos, drama y juego de roles además de entrevistas.

Algunas de las ideas que se muestran a continuación se encuentran entre las muchas que se han presentado en recientes investigaciones y están destinadas a motivar a los profesores a crear las suyas propias.

\section{Video}

A través del uso de videos, se proveen pistas del contexto que pueden estimular la predicción o especulación sobre la situación o mensaje. Butler-Pascoe and Wiburg (2003) describen una variedad de ejercicios con el uso del video. Sugieren que a los estudiantes de lenguas extranjeras se les pueden mostrar una escena inicial de una película de aventuras. 
Posteriormente el profesor preguntará a sus estudiantes que predigan que pasará después de esa escena, con la opción de mostrar la escena siguiente con sonido o sin él.

A un grupo se les mostrará la escena sin sonido (esto permitirá que puedan especular analizando el lenguaje corporal de los actores) y al otro grupo solo se les mostrará el audio, o sea no se les permitirá ver la escena, solo escucharla (los mismo trataran de imaginar o imitar las escenas del audio). Butler-Pascoe and Wiburg (2003) predicen que los estudiantes eventualmente serán capaces de realizar sus propias producciones para demostrar las interacciones sociales, mirando las escenas repetidamente para analizar la efectividad de sus mensajes.

\section{Drama}

Estas actividades les permitirán a los estudiantes desarrollar descubrimientos y discusiones. En la primera actividad, los estudiantes desarrollarán las habilidades de improvisación, aprender a escuchar y reaccionar espontáneamente, al mismo tiempo que aprenden nuevo vocabulario en el contexto. Para comenzar un estudiante se incorpora en el centro de sus compañeros y realiza mímicas de una acción, el resto del grupo lo sigue al copiar los gestos que realiza, hasta que uno descubre la acción. Este estudiante pasa al centro con una nueva acción y así sucesivamente. (Culham, 2002).

La próxima actividad se enfoca en la atención de los estudiantes en la importancia del comportamiento no verbal en la codificación y decodificación de las emociones. Esta actividad alienta a los estudiantes a observarse unos a otros y a interactuar como grupo, sin necesidad de ponerlos a actuar. Como grupo ellos exploran como las emociones se manifiestan, como las mismas influencian la interpretación física,

y exploran ligeramente las distinciones entre las palabras que expresan emoción. Se les pedirá a los estudiantes que relacionen la expresión de la emoción y el lenguaje corporal. Para el comienzo un voluntario escribirá en la pizarra una emoción y se le pedirá al resto de la clase que agreguen más emociones relacionas con la escrita, pero a través de la expresión facial. (Culham, 2002).

\section{Entrevistas}

Las entrevistas son una forma efectiva para que los estudiantes aprendan acerca de los demás en el aula. A través de esta actividad los estudiantes conocerán que la comunicación en situaciones novedosas con un nuevo idioma puede ser ambigua, y a veces frustrante y necesitarán de nuevas vías para llegar al significado.

El primer paso será formar parejas de estudiantes y pedirles que traten de encontrar tanto información como puedan de su pareja, pero con la condición que no se les permitirá hablar ni tomar notas. Después de 20 minutos, los estudiantes darán la in- 
formación obtenida al resto del grupo, chequeando que dieron y recibieron mensajes claros. La información imprecisa necesita ser aclarada. A continuación, una discusión de retroalimentación resaltará la importancia de la CNV a los estudiantes.

\section{CONCLUSIÓN}

La mayoría de los cursos de lenguas extranjeras, incorporan a sus contenidos textos, estructuras y unidades de la lengua, que conservan y transmiten los particulares significados culturales de hechos y fenómenos geográficos, históricos, folclóricos, religiosos, políticos, económicos y sociales. Sin embargo, se omiten otras unidades significativas de naturaleza no verbal, que intervienen en la comunicación interpersonal, cuya convencionalidad cultural y valor simbólico son reconocidos por los hablantes de la lengua y forman parte de su identidad cultural.

Así pues, la formación comunicativa profesional, orientada tradicionalmente hacia el logro de la eficacia en el desarrollo de habilidades en una lengua extranjera a partir de lo singular, adquiere nueva perspectiva con el reconocimiento de la necesidad de potenciar en la comunicación los elementos no verbales.

El reconocimiento de lo general, de carácter universal en ellos, se concreta tomando en consideración lo étnico-cultural, que en esencia no es expresión de oposición, sino manifestación de otros nuevos significados en otros nuevos signos, conformados en un proceso histórico-cultural de desarrollo, cuya riqueza puede ser aprendida a través de esos propios signos. Esto tributa a potenciar la función educativa del proceso de formación comunicativa de profesionales de lenguas extranjeras, con nuevos aspectos interculturales de dichalengua.

\section{REFERENCIAS BIBLIOGRÁFICAS}

Birdwhistell, R. (1952). Introduction to kinesics.

Jürgen, R. and Weldon, K. (1956). Nonverbal communication.

Edward, Hall. (1959). The silent language.

Brunori, P., Ladavas, E. y Ricci, P. (1979). Differential aspects in the recognition of facial expression of Emotions. The Italian Journal of Psychology.

Butler-Pascoe, E., y Wiburg, K. (2003). Technology and teaching English language learners. Boston, Massachusetts, USA: Allyn and Bacon/Pearson.

Chaussat, P. (1966). Notas sobre la pantomima. La Habana: Editora del Consejo Nacional de Cultura, Editorial Nacional de Cuba, 
Culham, C. (2002). Coping with obstacles in drama-based ESL teaching: A nonverbal approach. In G. Brauer (Ed.) Body and language: Intercultural learning through drama (pp. 95-112). Westport, CT: Ablex.

Darwin, C. (1872). The expression of the Emotions of man and animals. London, Murray.

Davis, F. (1978). La comunicación no verbal. Alianza Editorial, Madrid.

Dino, G. y Ricci, P. (1981). Culture and sex effect in recognizing emotions by facial and gestural cues. The IItalian Journal of Psychology, vol. VIII, n.2, august.

Eibl-Eibesfeldt, I. (1970). Ethology: the biology of behavior, N.Y., Holt, Rinehart and Winston.

Ekman, P. (1972). Universal and cultural differences in facial expressions of emotions. En: Nebraska Symposium on Motivation, ed. J.Cole, Lincoln: University of Nebraska.

Ekman, P; Sorenson, E. y Friesen, W. (1969). Pancultural elements in facial displays of emotions. Science, 164.

Engels, F. (1976). Dialéctica de la naturaleza. En: C. Marx y F. Engels. Obras Escogidas. Ed. Progreso, Moscú.

Hall, J. (1978). Gender effects in decoding nonverbal cues. Psychological Bulletin, 85.

Henley, N. (1977). Bodily politics: Power, sex and nonverbal communication. Englewood Cliffs, New Jersey Prentice Hall.

Henley, N y Freedman, J. (1976). The sexual politics of interpersonal behavior. En: S.Cox (ed.), Female psichology: the emerging self. Chicago: Science research associates inc.

Knapp, M. (1980). La comunicación no verbal: el cuerpo y el entorno. Editorial Paidós, 1980.

Jürgen, R. and Weldon K. (1956). Nonverbal Communication.

Lahullier, E. (1985). La danza y el combate. Revolución y Cultura. La Habana. Cuba. 